\title{
ДИСКУРС УСТОЙЧИВОГО РАЗВИТИЯ: СЕМИОЗИС КОММУНИКАЦИИ В МЕДИЙНОМ ПРОСТРАНСТВЕ
}

\section{THE DISCOURSE OF SUSTAINABLE DEVELOPMENT: SEMIOSIS IN COMMUNICATION IN THE MEDIA SPACE}

\section{S. Kliminskaya}

Summary: The article is devoted to the analysis of the metadiscourse of sustainable development forming in the media. The author considers the features of the modern media environment, analyzes the nature of the discourse of sustainable development as a metaphenomenon, defines the properties of hybrid concepts as semiotic signs, determines groups of verbal signs functioning in the metadiscourse of sustainable development. The article emphasizes the role of media personality in the formation of the trajectory of meaning in creolyzed texts that make up the metadiscourse of sustainable development.

Keywords: media discourse, sustainable development, hybrid concepts, creolized text, semiotics.

\author{
Климинская Светлана Леонидовна \\ к.филол.н., дочент, МГИМО МИД РФ \\ kvi62@inbox.ru
}

Аннотация: Статья посвящена анализу метадискурса устойчивого развития, развертывающегося в средствах массовой информации. Автор рассматривает особенности современной медиасреды, анализирует природу дискурса устойчивого развития как метафеномена, выявляет свойства гибридных концептов как семиотических знаков, определяет группы вербальных знаков, функционирующих в метадискурсе устойчивого развития. В статье роль подчеркивается особая роль медиаперсоны в формировании траектории смысла в креолизованных текстах, составляющих метадискурса устойчивого развития в СМИ.

Ключевые слова: медиадискурс, устойчивое развитие, гибридные концепты, креолизованный текст, семиотика.
Д искурс устойчивого отражает усилия мирового сообщества выработать стратегию ответственного развития с целью противостоять глобальному сохранить планету для будущих поколений с учетом моральных и нравственных приоритетов национальных государств посредством межкультурного диалога. Представляя собой комплексный феномен, объединяющий несколько институциональных субдискурсов, дискурс устойчивого развития реализуется в различных формах от профессиональной дискуссии между специалистами и учеными до полемики между представителями общественных и государственных организаций. Необходимость популяризировать идею устойчивого развития, а также потребность в постоянном обмене информацией, свойственная современному информационному обществу, способствуют активному развертыванию дискурса устойчивого развития в средствах массовой информации.

Медиапространство является благоприятной средой для функционирования дискурса устойчивого развития как полилогической коммуникативной среды, где реализуются такие свойства данного дискурса как междисциплинарность, социальная прагматическая направленность, а также его когнитивные и аксиологические особенности [12, с. 199-210; 22]. В связи с усилением цифровизации СМИ медиапространство становится качественно новым типом информационного взаимодействия, позволяя объединить принципиально разные форматы речевого взаимодействия [7, с. 22-29].
В медиадискурсе информация о проблемах устойчивого развития и путях их решения представлена креолизованными произведениями различных жанров: новостные сообщения, аналитические материалы и тимскомментарии, авторские статьи ("features"). Подобные произведения включают текст, графическое изображение, звуко- и/или видеоряд, что в условиях медиаконвергенции $[4,20]$ позволяет представить информацию цифровым контентом в информационно-коммуникативной среде. Такой способ подачи информации значительно увеличивает число участников коммуникативного процесса по вопросам устойчивого развития и предоставляет им разнообразные возможности для производства, хранения и распространения идей в различных форматах.

Медиаконвергенция информационной среды наряду с возможностью комбинировать различные системы кодирования информации в медиа пространстве способствуют развертыванию метадискурса УР [12, с. 12] как особой среды, где отражаются и взаимодействуют несколько реальностей [15, с. 327], возможно преодоление установленных рамок восприятия информации, а также создание новой действительности [9, с. 314-322]. Одновременное использование вербального кода и невербальных средств кодирования дает возможность быстро и точно передавать информацию. Кроме того, мультимедийные возможности современных СМИ позволяют метафорически осветить события, а целевой аудитории самостоятельно их интерпретировать, анализируя раз- 
личные образы, смыслы и посылы. Этому служат интертекстуальные включения из различных институциональных субдискурсов устойчивого развития, демонстрируя природу дискурса устойчивого развития как метафеномена, а также семантическая структура дискурса устойчивого развития, в основе которой лежит тематическая доминанта [5, с. 37-38] дискурса устойчивого развития.

Тематическая доминанта, несмотря на жанровое разнообразие текстов, составляющих дискурс устойчивого развития, опирается на идею о коллективной ответственности, заключающейся в осознании каждым современным человеком важности за претворение в жизнь принципов устойчивого развития. В дискурсе эта идея реализуется соответствующим концептом, который в сочетании с концептом устойчивое развитие, составляет основу семантической структуры метадискурса устойчивого развития [12, с. 173$]$.

Семантическая структура метадискурса устойчивого развития включает концепты, образующиеся и функционирующие в дискурсе устойчивого развития и отражающие явления, и тенденции, направленные на воплощение стратегии устойчивого развития. В семантической структуре можно выделить два типа концептов. Первая группа включает базовые концепты, принадлежащие институциональным субдискурсам и представляющие соответствующие семантические поля. Например, семантическую основу экологического субдискурса составляют такие концепты, как: carbon emission, greenness, carbon tax, ecology и др. Другую группу представляют гибридные концепты, образующиеся на стыке субдискурсов УР [12]. Примерами гибридных концептов могут служить такие сочетания, как: green technologies, sustainable development, renewable energy, food security, green technologies international standards, green world, ecorefugee, ecoterrorism и др. При этом, в мультимодальном медиапространстве гибридные концепты становятся семиотическими знаками, функционирующими, наряду с другими элементами различных семиотических систем (видео-, аудио-, символы и графическая информация и т.п.), что расширяет границы восприятия текстового сообщения и задает определенный прагматический вектор.

При развертывании дискурса устойчивого развития в СМИ поликодовость играет особую роль, так как способствует формированию тематической доминанты, что делает метасдискурс УР тематически устойчивым, а также дает возможность отобразить реальные события, воссоздать их причины и спрогнозировать последствия, и, в месте с тем, мифологизировать описываемые события и явления на основе их эмоциональной рефлексии реципиентами [6, с. 127-143].

Метадискурс устойчивого развития является примером эмотивной коммуникации, так как развертывается вокруг социально значимых вопросов и предполагает рефлексию и реакцию реципиента информации [14], т.е. формирование мнения, отношения, осуществления ответных действий и т.п. Ярко выраженное референциальное значение имеют гибридные концепты, так как позволяют соотнести значения концепта с определенным классом явлений, что предполагает оценку данных явлений и, соответственно, наделяют оценочностью значение гибридного концепта. Данное свойство гибридных концептов дает возможность рассматривать гибридный концепт как семиотический символ, функционирующий в многомерном языковом пространстве - метадискурсе УР.

Интерпретация информации в среде СМИ, формирующейся в ходе дискурсивной деятельности при развертывании метадискурса устойчивого развития и представленной элементами различных семиотических систем, происходит за счет актуализации смысловых связей между всеми перечисленными элементами дискурса, что ведет к символизации смысла сообщения и задает определенный вектор его восприятия. Анализ языкового материала с опорой на уже проведенные исследования $[1,16,18]$ демонстрирует наличие в дискурсе устойчивого развития символов различного характера:

- специализированные вербальные знаки - базовые концепты различных субдискурсов: war, country, government, environmental control, carbon emission, business, technology, business $u \partial p$.

- агональные знаки - знаки вербальной агрессии (угроза, ярлыки, предупреждение, ироническая номинация и т.п.), которые типичны для политического субдискурса, однако все больше проникают и в другие субдискурсы и становятся привычными для метадискурса устойчивого развития, развертывающегося с СМИ, такие как empty words, threat, poverty, hunger, maternal deaths, fight (for rights) $u \partial p$.

- объединяющие знаки - знаки-символы, например флаги, эмблемы, цвета, логотипы предприятий и т.п., позволяющие ассоциировать коммуниканта с определенной партией, государством, общественным движением, компанией, брендом и т.п.

- знаки ориентации - ситуативные концепты, символизирующие какую-либо доктрину или общественную позицию: SDGs (the sustainable development goals), MDGs (the Millennium Development Goals), Addis Ababa action agenda, UNESCO, IMF research "Women in Finance: A Case for Closing Gaps" u $\partial p$.

- неспециализированные вербальные знаки - институциональные термины и гибридные концепты дискурса устойчивого развития, формирующие эмотивный фон и общественные аксиологические принципы: greenhouse gas, ecowarriors, carbon footprint, green technologies, food security, deep ecology, sustainable job creation, ecosystem. 
Наличие в метадискурсе устойчивого развития концептов-символов в сочетании с элементами других семиотических систем способствует созданию особого эмоционального фона в поддержку идеи о коллективной ответственности, что в свою очередь создает метамотивацию у аудитории к формированию коллективной ответственности, а также свидетельствует о пластичности метадискурса устойчивого развития, под которым мы понимаем свойство дискурса направлять реципиента к определенной прагматической цели, опираясь на чувственное восприятие вербальных и невербальных элементов, составляющих данный дискурс, создавая определенный смысловой и прагматический ландшафт. Элементы, принадлежащие различным семиотическим системам, соединяются в своеобразный пластический жест и задают траекторию смысла [19].

Траектория смысла формируется за счет актуализации имманентных связей между составляющими ее элементами различных семиотических структур и опирается на множество философских понятий, определяющих отношения между элементами системы знания современного человека. Трансляция знания в определённом прагматическом русле с использованием различных систем кодирования в информационном пространстве, формирующимся СМИ, создает определенную аксиологическую систему координат в условиях лингвокультурной глобализации [5].

Механизм формирования траектории смысла четко прослеживается в политическом субдискурсе устойчивого развития. В силу своей деятельности политики касаются различных сфер общественной жизни, а проблема устойчивого развития сегодня стала одной из наиболее актуальной проблем и широко обсуждается не только специалистами и учеными, но и часто используется политиками как аргумент как при проведении предвыборных кампаний, так и при реализации своих программ.

Анализируя предвыборную программу Дж. Байдена, размещенную на сайте политика (https://joebiden.com/ clean-energy/), мы находим, что президент уделяет большое внимание проблемам защиты окружающей среды, претворению в жизнь стратегий устойчивого развития, кооперации с другими странами и правительствами по вопросам зеленой энергетики. Информация изложена нейтральным языком и направлена на актуализацию многочисленных проблем и путей их решения. Данное медиа произведение насыщено специализированными вербальными знаками экологического дискурса (hydro dam (гиброплотина), hydroelectric power, ecosystems, pollution, global heating, climate break down); агональные знаки (economic crisis, climate crisis, hoax, existential threat); присутствуют знаки ориентации (слоган 'Battle for the soul of the nation" и название партии Democrats), позволяющие быстро определить общую позицию и стратегию пар- тии и ее лидера; кроме того, в данном тексте имеется большое количество гибридных концептов (heat stress, clean energy economy, green space, zero-emissions public transportation, a carbon pollution-free power sector, renewable hydrogen, climate-smart agriculture и др.). Концентрация вербальных знаков на фоне лаконичного оформления сайта, который выдержан в бело-синих тонах, ассоциирующихся с уверенностью и спокойствием, позволяют автору данного сайта создать прагматический ландшафт и смысловую траекторию с целю убедить реципиента в необходимости внедрения стратегии "Устойчивой инфраструктуры и справедливой чистой энергетики будущего", предлагаемой партией Демократов и ее лидером.

Однако, в условиях интенсификации лингво- и социокультурных контактов, которые реализуются в том числе и в СМИ, формирование траектории смысла во многом зависит от личности медиаперсоны.

В креолизованном дискурсе СМИ, каковым является дискурс устойчивого развития, именно публичность медиасубъекта, свойства его речевой деятельности, а также поведенческие особенности [2], становятся точкой бифуркации в дискуссионном процессе. В дискурсе СМИ осуществляется вербализация языковой личности, что отражает восприятие и когнитивную обработку коммуникантом информации, имеющейся и получаемой в ходе дискуссионного процесса. Технические возможности современных средств массовой коммуникации позволяют сочетать одновременно вербальный код с невербальной составляющей речевой деятельности коммуниканта, представленной жестами, интонацией, мимикой, скоростью речи коммуниканта, а также со средствами других семиотических систем. Подобное комбинирование элементов в единый ассоциативный комплекс способствует медиатизации [3] коммуниканта, т.е его трансформации в медиаобъект с последующим формированием символа, который будет интерпретироваться в рамках определенной смысловой траектории.

Заданная директива интерпретации [21] образа медиаперсоны как семиотического знака свидетельствует о пластичности медиадискурса, однако вербально-семантические, когнитивные и прагматические особенности языковой личности [8, с. 245] в дискурсе устойчивого развития оказывают влияние на течение дискуссионного процесса.

Наиболее ярким примером медиатизации коммуниканта в дискурсе устойчивого развития, развертывающегося в СМИ, является появление медиаперсоны Греты Тунберг. Выступление шведской школьницы, известной своей борьбой с изменениями климата на планете, на климатическом саммите ООН в 2019 году стало громким событием, которое широко освещалось в средствах 
массовой информации. Непродолжительный монолог подростка вызвал неоднозначную реакцию аудитории в силу необычности личности автора выступления, эмоциональной окраски речи девушки и неординарности посыла выступления, выраженного в форме обвинения, неприкрытой ненависти и угроз.

Семантический анализ выступления Греты Тунберг, как медиасубъекта, выявляет персональные особенности восприятия проблем, вызванных изменениями климата, и демонстрирует оригинальную когнитивную обработку информации о проблемах устойчивого развития. В речи девушки присутствуют концепты, принадлежащие экологическому субдискурсу устойчивого развития (ecosystem, mass extinction, emissions, warming, air pollution и др.), что свидетельствует об однобоком понимании девочкой проблем. Однако появление в ее рассуждениях концептов из экономического субдискурса (money, economic growth), а также гибридного концепта дискурса устойчивого развития (climate justice), дает основания предположить, что юная активистка осознает широту спектра причин климатических изменений на планете и необходимость комплексносных решений. При этом, речевые стратегии убеждения [10], выбранные школьницей для воздействия на аудиторию, строятся на обвинениях (How dare you!...; You have stolen my dreams...) и угрозах (...we'll be watching you!..; We will not let you get away with this...).

Агрессивное речевое и социальное поведение Греты, сопровождавшееся соответствующими мимикой и интонацией, способствовало формированию двоякого отношения к данному событию. С одной стороны, появление представителя молодого поколения, выражающего озабоченность, проблема сохранения планеты, на мероприятии подобного уровня сделало ее символом движения по борьбе с экзистенциальным кризисом. Выступление девушки на саммите $\mathrm{OOH}$ на фоне символов международной организации и эмблемы устойчивого развития в присутствии высокопоставленных государственных деятелей и других медиаперсон сформировало положительную оценочную доминанту Греты Тунберг, как медиаобъекта. С другой стороны, особенности вербализации и речевое поведение данной языковой личности в сочетании с элементами невербальной коммуникацией девушки сформировали негативный ассоциативный потрет [17] коммуниканта за счет образования негативного эмотивного фона вокруг данной медиаперсоны - Грета стала антисимволом "зеленого движения". Это вызвало большой отклик в международном сообществе не только среди политиков и специалистов по охране окружающей среды, но и стало отправной точкой в развитии нового витка дискуссионного процесса в СМИ по вопросам охраны окружающей среды и стратегии устойчивого развития.

Таким образом, развертывающийся в средствах массовой информации метадискурс устойчивого развития представлен креолизованными текстами различных жанров, сочетающими вербальные и невербальные элементы, что обусловливает полноту передачи информации и образность освещения общественных процессов. Вербальные семиотические знаки представлены гибридными концептами, которые составляют семантическую структуру метадискурса устойчивого развития и определяю его эмотивный фон. Эмотивный потенциал гибридных концептов, как семиотических знаков, используется коммуникантами при построении стратегий убеждения. Данное свойство вербальных знаков способствует формированию метамотивации у аудитории и обусловливает определенный ракурс восприятия дискуссии по проблемам устойчивого развития за счет формирования траектории смысла. При этом траектория смысла зависит от речевого поведения и особенностей языковой личности медиаперсоны, участвующей в коммуникативном процессе.

\section{ЛИТЕРАТУРА}

1. Алекберова И.Э., Тимакина 0.А. Символика политического дискурса: семиотический подход // Вестник PMAT. 2017. №3. URL: https://cyberleninka.ru/ article/n/simvolika-politicheskogo-diskursa-semioticheskiy-podhod (дата обращения: 28.10.2020).

2. Алексеева Е.А. Концепция языковой личности в исследованиях дискурса сми https://nsu.ru/xmlui/bitstream/handle/nsu/9464/13.pdf

3. Бакеева Д.А. Феномен медийной личности как субъект медиакультуры (на примере образов телеведущих) / Д.А. Бакеева // Новый этап развития науки : Сборник статей по материалам международной научно-практической конференции, Калининград, 07 апреля 2017 года. - Калининград: 06щество с ограниченной ответственностью «Научное партнерство «Апекс», 2017. - С. 160-163.

4. Баранова Е.А. Медиаконвергенция как системообразующий фактор трансформации института СМИ : специальность 10.01 .10 «Журналистика»: автореферат диссертации на соискание ученой степени доктора филологических наук / Баранова Екатерина Андреевна. - Москва, 2019. - 30 с.

5. Добросклонская Т.Г. Динамика языковых процессов в условиях лингвокультурной глобализации / Т.Г. Добросклонская // Диалог культур и цивилизаций : Материалы Международной научно-практической конференции, Москва, 15-16 марта 2019 года / Под общей редакцией Ч.Б. Далецкого, А.Ю. Платко. Москва: Московский государственный лингвистический университет, 2019. - С. 259-264.

6. Добросклонская Т.Г. Медиалингвистика: системный подход к изучению языка СМИ (современная английская медиаречь) : учебное пособие / Т.Г. Добросклонская. - Москва : Флинта : Наука, 2008. - 263 с. : ил.; 21 см.; ISBN 978-5-9765-0273-4 (Флинта)

7. Добросклонская Т.Г. Медиалингвистика: теория, методы, направления / Т.Г. Добросклонская. - Москва : «КДУ», «Добросвет», 2020. - 178 с. - ISBN 978-5- 
7913-1128-3. - DOI 10.31453/kdu.ru.91304.0107.

8. Караулов Ю.Н. Русский язык и языковая личность. М.: Наука, 1987. 262 с.

9. Кастельс М. Информационная эпоха: экономика, общество и культура: Пер. с англ. под науч. ред. 0.И. Шкаратана. - М.: ГУ ВШЭ, 2000. - 608 с.

10. Климинская С.Л. Лингвостилистические средства реализации стратегий и тактик убеждения в аргументативном дискурсе (на материале англоязычных телевизионных дискуссий): специальность 10.02.04 «Германские языки»: диссертация на соискание ученой степени кандидата филологических наук / Климинская Светлана Леонидовна. - Москва, 2010. - 215 с.

11. Климова И.И., Мельничук М.В. Средства вербализации рекламного дискурса финансовых услуг // Филологические науки. Вопросы теории и практики. 2019. Т. 12. № 12. С. 335-341.

12. Концептология в современных гуманитарных исследованиях: лингвистика и лингводидактика / 0.В. Куликова, М.В. Романова, С.Л. Климинская [и др.]. Москва : Общество с ограниченной ответственностью «Издательство Прометей», 2021. - 352 с. - ISBN 978-5-00172-159-8.

13. Куликова 0.В., Климинская С.Л. Концептуальное взаимодействие в динамике дискурса устойчивого развития (на материале английского языка) // Современная наука: актуальные проблемы теории и практики. Гуманитарные науки. 2018. №3. URL: http://www.nauteh-journal.ru/index.php/ru/--gn1803/4394-a

14. Литвинчук И.Н. Междисциплинарный анализ эмотивного дискурса: основные черты в парадигме когнитивной и прагмалингвистики // Ученые записки Крымского федерального университета имени В. И. Вернадского. Филологические науки. 2017. №4. URL: https://cyberleninka.ru/article/n/ mezhdistsiplinarnyy-analiz-emotivnogo-diskursa-osnovnye-cherty-v-paradigme-kognitivnoy-i-pragmalingvistiki

15. Лотман Ю.М. История и типология русской культуры / Ю.М. Лотман. - Искусство-СПБ, 2002. - 768 с.; ISBN 5-210-01527-0

16. Мельничук М.В., Климова И.И., Белогаш М.А. Методологические подходы к многоаспектному анализу манипулятивного потенциала языка рекламы // Российский гуманитарный журнал. 2019. Т. 8. № 5. С. 334-342.

17. Салихова Э.А. Лингвокультурологическая составляющая ассоциативного портрета билингва // Вестник Башкирск. ун-та. 2006. №3. URL: https:// cyberleninka.ru/article/n/lingvokulturologicheskaya-sostavlyayuschaya-assotsiativnogo-portreta-bilingva

18. Шейгал Е.И. Семиотика политического дискурса : автореферат дис. ... доктора филологических наук : 10.02.01, 10.02.19 / Волгоград. гос. пед. ун-т. - Волгоград, 2000. - 31 с.

19. Эпштейн М. Пластичность философского текста: почему одни авторы более читаемы, чем другие // Звезда, 2014, №1. URL: https://magazines.gorky. media/zvezda/2014/1/plastichnost-filosofskogo-teksta-pochemu-odni-avtory-bolee-chitaemy-chem-drugie.html

20. Юферева А.С. Медиаконвергенция: основные подходы к определению понятия // Антиномии. 2016. №2. URL: https://cyberleninka.ru/article/n/ mediakonvergentsiya-osnovnye-podhody-k-opredeleniyu-ponyatiya.

21. Eco U. The Role of the Reader: Explorations in the Semiotics of the Text/ Indiana University Press / U/Eco/ - URL: http:// http://www.goodreads.com/bbok/ show/10528.The_Role_of_the_Reader страницы (https://cyberleninka.ru/article/n/semioticheskaya-klassifikatsiya-znakov-novyy-aktsent/viewer)

22. Yudina N.V., Velnichuk M.V., Seliverstova 0.A. Language policy and planning in Russia, China and the USA through the lens of mass media of the 21-st century // Journal of Social Studies Education Research. 2020. T. 11. № 3. C. 242-269.

( ) Климинская Светлана Леонидовна (kvi62@inbox.ru). 